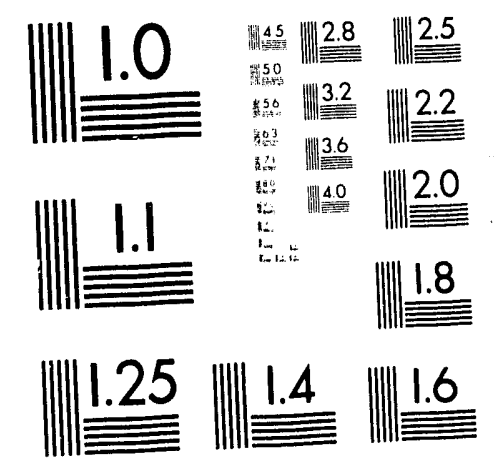



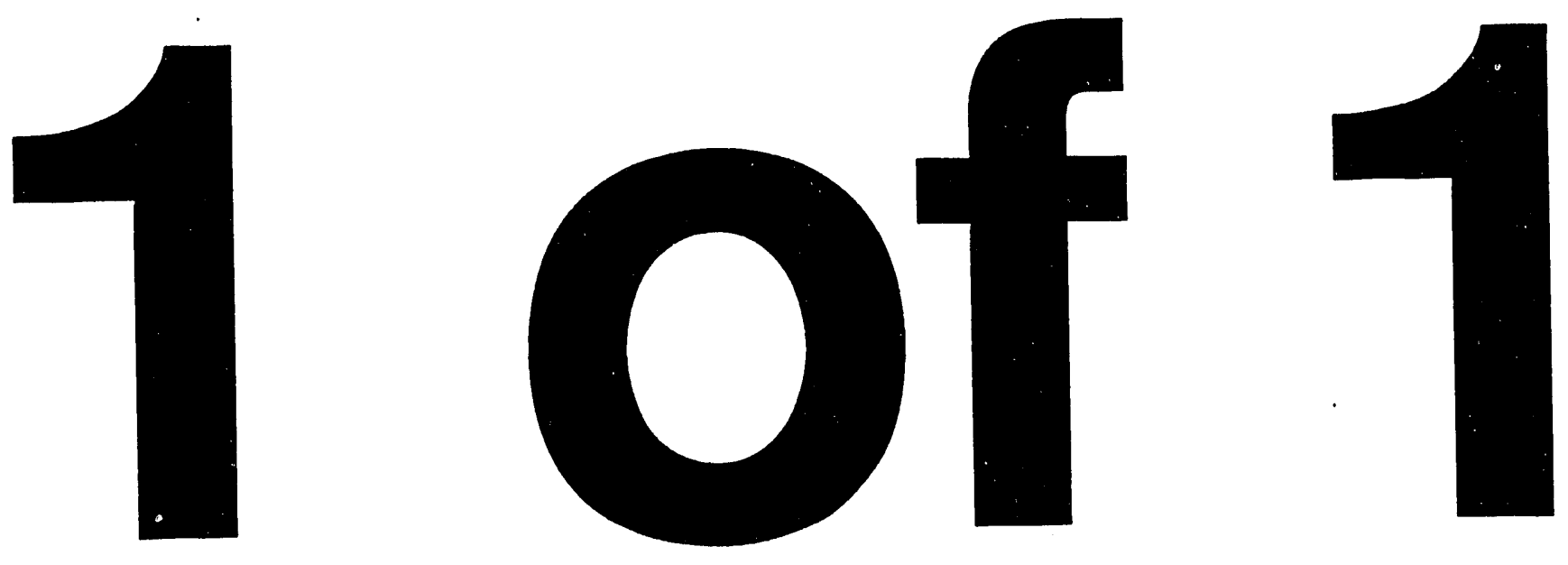


\title{
DEVELOPMENT OF SILICON NITRIDE COMPOSITES WITH CONTINUOUS FIBER REINFORCEMENT
}

\author{
T. L. Starr, D. L. Mohr, W. J. Lackey, and J. A. Hanigofsky \\ Materials Science and Technology Laboratory \\ Georgia Tech Research Institute \\ Atlanta, Georgia 30332
}

October 1993

Research Sponsored by the U. S. Department of Energy, Fossil Energy

Advanced Research and Technology Development Materials Program

\author{
Report Prepared by \\ GEORGIA TECH RESEARCH INSTITUTE \\ Georgia Institute of Technology \\ Atlanta, Georgia 30332 \\ under \\ Sub-contract 19X-00184C
}

for

OAK RIDGE NATIONAL LABORATORY

Oak Ridge, Tennessee 37831 managed by

MARTIN MARIETTA ENERGY SYSTEMS, INC.

for the

U. S. Department of Energy

under Contract No. DE-AC05-840R21400 
LIST OF FIGURES

LIST OF TABLES

SUMMARY

1

INTRODUCTION

SILICON POWDER/NTTRIDING PROCESS DEVELOPMENT 6

FIBER DEGRADATION IN THE NITRIDING ENVIRONMENT

8

$\begin{array}{lc}\text { FIBER COATINGS } & 8\end{array}$

FABRIC REINFORCED COMPOSITES 9

UNIAXIAL CONTINUOUS FIBER COMPOSITES

DISCUSSION AND CONCLUSIONS

REFERENCES 


\section{LIST OF FIGURES}

1. Chemical vapor deposition system used to deposit $\mathrm{C} / \mathrm{SiC}$ coatings on Nicalon fibers 10

2. Schematic of the reagent introduction path used to deposit $\mathrm{C}+\mathrm{SiC}$

3. Electron micrograph shows $\mathrm{C} / \mathrm{SiC}$ coating on Nicalon fiber after nitriding in composite

4. Filament winding apparatus for reaction sintered composites

5. Uniaxial Nicalon/reaction sintered silicon nitride microstructure

6. C-ring test configuration used to test tubular samples

7. Parallel and perpendicular testing direction for fabric reinforced composites

8. Crack propagation in uniaxial Nicalon/reaction sintered silicon nitride composite 


\section{LIST OF TABLES}

1. SELECTED DATA FOR ATTRITOR MILLED SILICON

2. FIBER PROPERTIES AFTER ENVIRONMENTAL EXPOSURE

3. CERAMIC FIBER CLOTHS USED FOR FABRICATION OF REACTION SINTERED SILICON NITRIDE COMPOSITES.

4. SUMMARY OF TYPICAL SILICON NITRIDE COMPOSITE PROPERTIES

5. FLAT PLATE UNIAXIAL COATED FIBER LAMINATES 


\section{SUMMARY}

Ceramic composites with improved fracture toughness compared to traditional ceramics continue to hold great promise for increasing the efficiency of fossil fuel utilization. Ease of fabrication is an important factor in such applications, especially for the relatively large and complex shapes used for fossil energy conversion systems. Reaction sintering to form silicon nitride is one of only a few ceramic processing routes that produces densification without reducing the volume of the green structure. This near-net-shape forming characteristic is critical for successful fabrication of fiber toughened composites where the reinforcement tends to restrain the shrinkage of the green body. However, complete nitridation of conventional silicon powder, that is, powder with a median diameter on the order of $7 \mu \mathrm{m}$, requires a long hold period at high temperature, and available ceramic fibers lose much of their strength under these conditions.

Our efforts have focused on fabrication of composites using ultrafine silicon powders prepared by attritor milling. This powder exhibits near full conversion to silicon nitride in less than three hours at a maximum temperature of $1200^{\circ} \mathrm{C}$. These processing conditions reduce degradation of polymer-derived reinforcement fibers compared to conditions required by conventional processes.

The influence of processing conditions on fiber properties and the use of fiber coatings to improve stability during processing as well as change the fiber-matrix interfacial properties has also been investigated. Selected nonoxide ceramic fibers were exposed to the nitriding environment. Tensile strengths of nitrided fibers showed significant strength loss compared to the as-received fibers.

Control of fiber degradation which occurs during composite processing and service conditions and control of the fiber-matrix interfacial strength are critical to the performance of ceramic composites. A possible solution to this problem involves design of a proper coating systems for the ceramic fiber/ceramic matrix system. A duplex carbon-silicon carbide coating was deposited via chemical vapor deposition. The continuous coating produced apparently reduced fiber degradation in processing as observed by electron microscopy, and modified the fiber-matrix adhesion as evidenced by more "graceful" failure characteristics and increased fiber pull-out observed on fracture surfaces.

Silicon nitride matrix composites have been fabricated using the reaction sintering process. Fabric reinforced laminates and filament wound plates and tubular shapes have

Research sponsored by the U. S. Department of Energy, Fossil Energy AR\&TD Materials Program, DOE/FE AA 151010 0, Work Breakdown Structure Element GT-1. 
been produced. In each case, an attritor milled silicon powder slurry is infiltrated into ceramic fiber preforms or tows, which are subsequently assembled to form a 3-D structure. The matrix can then be reaction sintered at moderate temperature $\left(1200^{\circ} \mathrm{C}\right)$ to form composites which have properties comparable to chemical vapor infiltration (CVI) densified composites, with reasonable strengths and graceful composite fracture behavior.

Critical factors in achieving good composite properties are effective impregnation of the multi-filament tows, fiber stability during processing, and fiber-matrix interfacial properties in the composite. Composite fabrication conditions and their relationship to composite density, pore size distribution, and mechanical properties have been examined.

Composites were initially fabricated by infiltrating ceramic fiber 2-D fabric preforms with a slurry of attritor milled silicon in ethanol. Layers of silicon powder impregnated fabric were stacked and compressed to form a flat-plate laminate. We fabricated fabric reinforced composites using five different fiber types: commercially available Nicalon ${ }^{\mathrm{TM}}$ and Tyranno $^{\mathrm{TM}}$ fibers from Nippon Carbon and Ube Industries, respectively, developmental HPZ fibers from Dow Corning, and carbon-coated Nicalon from two sources. Microscopic examination of the fabric reinforced composites generally showed good density between cloth layers but significant porosity within individual fiber tows. All fabric reinforced specimens exhibited some non-brittle fracture behavior in flexure, i.e. continued to carry load after the initial crack generation.

Subsequent samples were produced via filament winding with uniaxial fiber orientation. Flat plate samples were produced with Nicalon, HPZ, and C/SiC-duplex coated Nicalon. Filament wound samples exhibited improved penetration of the matrix material into the regions inside of each fiber bundle. These samples had strengths as high as $195 \mathrm{MPa}$ in four point flexure. Significant strength retention was noted after the maximum load had been attained. The composite containing the duplex $\mathrm{C} / \mathrm{SiC}$ coated fiber exhibited the most "graceful" composite fracture characteristics of the filament wound flat plate samples.

Tubular samples were also produced via filament winding with Nicalon reinforcement. These samples also exhibited graceful failure characteristics. All samples remained intact after maximum load was imposed. Failure was apparently interlamellar, with the fracture path passing through the matrix material.

Because the fracture process in the filament wound samples involved interlamellar fracture through the matrix, flexure testing is very sensitive to matrix density and can not be used to judge tensile properties. Tensile test samples have been prepared to evaluate those properties. 


\section{INTRODUCTION}

Ceramic composites with improved fracture toughness compared to traditional ceramics continue to hold great promise for increasing the efficiency of fossil fuel utilization and other high temperature applications. One particular application is for gas turbine engine components utilizing a direct combustion or gasification/combustion process. Turbine components and vanes in the gas path will have to maintain their integrity at high temperatures and in aggressive chemical environments. Fiber-reinforced ceramics offer increased toughness and damage tolerance while maintaining the high temperature capability and chemical stability inherent in ceramic materials.

Ease of fabrication is an important factor in producing the relatively large and complex shapes used for fossil energy conversion systems. Near-net-shape fabrication techniques are needed that will produce a uniform matrix microstructure and provide better distribution of load to the reinforcing fibers. Densification methods such as chemical vapor infiltration (CVI) of a fibrous preform can produce samples with very good properties. ${ }^{1}$ Under development for several years, one variation of this process (isothermal) is commercially available from several vendors, while an improved process (forced flow/thermal gradient) is approaching commercialization. However, the nature of these processes limits the production speed and size of composites made.

For some applications, silicon nitride matrix composites may offer improved capabilities compared with silicon carbide matrix composites. Although the properties of these materials vary considerable within each class of material, silicon nitride is generally tougher than silicon carbide, has lower thermal conductivity and expansion, and better oxidation resistance. Attempts to densify silicon nitride composites using CVI have not matched the success achieved with silicon carbide. A fundamental problem is that under conditions necessary for infiltration, silicon nitride deposits as an amorphous phase. This amorphous form is unstable at higher temperatures and generally has poor mechanical properties.

An alternative processing scheme for silicon nitride for is reaction sintering, whereby silicon powder is converted to nitride by reaction in a nitrogen atmosphere. This conversion process produces a fully crystalline silicon nitride phase. Because the nitride occupies $23 \%$ greater volume than the silicon, densification occurs without a reduction in bulk volume. 
This feature makes reaction sintering an attractive process for near-net-shape fabrication of composites.

Two factors have limited prior application of reaction sintering to produce ceramic composite. Standard nitriding temperatures $\left(1350-1400^{\circ} \mathrm{C}\right)$ and times (days) are too severe for the small diameter polymer-derived ceramic fibers that have been developed for composite applications. Also, typical silicon powders have a median particle diameter in the range $10-15 \mu \mathrm{m}$ which is too coarse to allow effective infiltration of the powder into the multifilament tows of $10-15 \mu \mathrm{m}$ filaments. One research group has avoided these problems by using more stable, large diameter CVD-derived fibers to make successful composites. ${ }^{2}$ While this application is limited by the high expense and difficulty in fabricating structure with the large diameter fibers, their success encourages further research.

Our previous results ${ }^{3}$ with ultrafine, silane-derived silicon powders (less than $0.05 \mu \mathrm{m}$ diameter) indicate full conversion in a short time at drastically lower temperatures. Other work with submicron silicon powder produced by thermal ${ }^{4}$ or laser ${ }^{5}$ decomposition of silane has shown rapid conversion to nitride at low temperatures. These powders, however, are produced by inherently high cost processes and yield low packing density, resulting in low density in the ultimate nitride. Submicron powder prepared by attritor milling has been $90 \%$ converted to silicon nitride at $1200^{\circ} \mathrm{C} .{ }^{6}$ In this case the nitriding time was long and no attempt was made to observe the nitriding kinetics with shorter processing schedules.

This work suggests that development of a fine, attritor milled silicon powder would hold a two-fold advantage for composite processing. First, the lower required processing temperatures and times would allow the use of multifilament polymer derived fibers tows and preforms. Secondly, the small particle size would provide for better impregnation of the multifilament tows. Our work has focused on this approach.

One advantage of reaction sintering is that results from small specimens should allow easy scale up to large shaped objects. Development of technology to fabricate such shaped objects while maintaining an appropriate distribution of the matrix and fibers in the composite is very important for commercialization of this process. The program adapted various fabrication methods used in the fabrication of polymer matrix composites to produce composite structures. For example, a candidate low cost, near-net-shape fabrication method 
for ceramic composite manufacturing involves coupling filament winding to the reaction sintering technique to densify the ceramic composite matrix.

Many of the currently available ceramic fibers are significantly degraded during composite densification?. For composite applications, it is critical to determine the fiber's actual stability in the processing environment and to tailor processing conditions to that fiber or to protect the fiber from that environment.

Control of the fiber-matrix interfacial properties is also important. Fiber coatings for ceramic composites have been utilized to control both the chemical and mechanical interaction of the fiber with the surrounding matrix ${ }^{8}$. Ceramic fibers have been coated with thin carbon coatings to reduce interfacial bonding, which enhances the "graceful" fracture of these composites. The stability of carbon coatings in a reaction sintered silicon nitride composite after nitriding and under mildly oxidizing conditions ( $1000^{\circ} \mathrm{C}$ for one hour) has been characterized. 9 This study showed that some carbon coatings can protect the fibers during processing, but are consumed if exposed to oxidizing service environments. It would be advantageous to develop a fiber coating which would protect the fibers during processing and through the lifetime of the component while not promoting strong bonding between the fiber and the matrix. Such a coating would need to provide a vapor barrier for the fibers, be nonreactive with the matrix during nitriding, and remain stable in the service environment. Carbon-carbon composite systems are often protected from environmental effects using multilayer coatings systems. ${ }^{10}$ In a similar manner, a "duplex" coating system for ceramic fibers in which a carbon coating is protected from environmental exposure by a continuous $\mathrm{SiC}$ coating has been examined in the research described below.

The program efforts include the development of silicon powder suitable for conversion to nitride under moderate processing conditions and the fabrication, processing, and characterization of composites using discontinuous silicon carbide whiskers, ceramic fiber tows, or ceramic fabric preforms.

Initially the program plan focussed on whisker reinforced material. However, as initial efforts produced substantial reduction of the time and temperature needed for the nitriding process, research shifted to continuous fiber reinforced composites. This fiber architecture promised more substantial gains in damage tolerance than whisker reinforced composites. 
The use of a polyorganosilazane preceramic binder as part of the reaction sintered composite system was also investigated, and was reported in an earlier topical report. ${ }^{11}$

The following describes research at the Georgia Tech Research Institute (GTRI) which has investigated the production of reaction sintered silicon nitride matrix composites reinforced with ceramic fabric and filament wound tows. Ceramic fibers have been coated using a CVD process. The strengths of a variety of ceramic fiber types after exposure to the nitriding environment have been characterized.

\section{SILICON POWDER/NITRIDING PROCESS DEVELOPMENT}

Silicon metal powder ( $7 \mu \mathrm{m}$ diameter) was obtained from Kemanord Industries (distributed by Superior Graphite Company). The silicon particle size was reduced using an attritor milling machine (model 01-HD) made by the Union Process Company with steel vessel and grinding media. The powders were dispersed in ethanol during the milling operation. The attritor milling process reduced the particle size such that nitriding could be performed using moderate processing conditions, reducing fiber degradation compared to ball milled powders. ${ }^{14}$ Monitoring the nitriding kinetics of the attritor milled powder showed near full conversion in less than two hours at a maximum temperature of $1250^{\circ} \mathrm{C}$ or less than four hours at $1200^{\circ} \mathrm{C}$. An attritor milled silicon powder (milled for 12 hours) was selected for the fabrication of initial fabric reinforced composites which had a mass average particle diameter of $1.5 \mu \mathrm{m}$ and BET surface area of $19 \mathrm{~m}^{2} / \mathrm{g}$.

Comparison of sedimentation velocity data with particle sizes based on transmission electron microscopy indicated that the particles may be agglomerated in the ethanol slurry. A series of organic dispersants with different chemical compositions were examined in the attritor milled silicon/ethanol system. Sedimentation experiments were performed to screen these additives. The best dispersant was evaluated in the attritor mill for various times. The resultant dispersions were evaluated to determine settling behavior, packing density and nitriding behavior.

The size distribution of particles milled for times from 12 to 48 hours were characterized using TEM, sedimentation experiments, and other methods. There was evidence of apparent 
agglomeration of particles based both on the relatively short time required for the particles to settle out of a dilute dispersion as compared to calculated settling velocities (based upon Stoke's law) and on the final settled volume which resulted (which was less than $32 \%$ dense). Dispersants with different chemical compositions were examined in the attritor milled silicon/ethanol system. Sedimentation experiments demonstrated a large variation in the settling velocity resulting from the addition of the various dispersants. The best dispersant of those examined was a sodium salt of a carboxy functional polymer (Tamol 731, Rohm and Haas) which decreased agglomeration based upon both decreased settling velocity and the increased packing density, which increased to $52 \%$ solids. Addition of Tamol decreased attritor milled particle size, and the time required to nitride the sample (Table 1).

TABLE 1

SELECTED DATA FOR ATTRITOR MILLED SILICON GREEN

\begin{tabular}{|c|c|c|c|c|c|c|c|}
\hline D & $\begin{array}{c}\text { MILLINC } \\
\text { DRY } \\
\text { (HRS) } \\
\end{array}$ & $\begin{array}{l}\text { TMME } \\
\text { ETHANOL } \\
\text { (HRS) }\end{array}$ & $\begin{array}{l}\text { VOL. WEIGHTED } \\
\text { PARTICLE SIZE } \\
\text { (MICRONS) }\end{array}$ & $\begin{array}{l}\text { DENSITY } \\
\text { PELLET } \\
\text { (G/CC) } \\
\end{array}$ & $\begin{array}{c}\text { TIME } \\
\text { TO NITRIDE } \\
\text { (MRS) } \\
\end{array}$ & $\begin{array}{c}\text { WEIGHT } \\
\text { GAIN } \\
(\mathscr{E}) \\
\end{array}$ & $\begin{array}{l}\text { NITRIDED } \\
\text { DENSITY } \\
\text { (G/CC) } \\
\end{array}$ \\
\hline 189 & 0 & 12 & 2.1 & & & 56 & \\
\hline 198 & 16 & 12 & & 1.39 & 1.6 & 49 & 2.07 \\
\hline 210 & 12 & 24 & 1.5 & 1.33 & 1.1 & 52 & 2.02 \\
\hline 212 & 24 & 25 & 1.0 & & & & \\
\hline 217 & 0 & 12 & & 1.37 & 4.1 & 57 & 2.15 \\
\hline 246 & 0 & $12^{*}$ & 1.3 & 1.30 & 2.0 & 56 & 2.03 \\
\hline
\end{tabular}

* WITH TAMOL DISPERSANT

The reaction bonding experiments were performed in a computer controlled nitriding system which has been described earlier. ${ }^{12}$ The system monitors nitriding parameters (pressure, moles of $\mathrm{N}_{2}$ gas used, temperature) on a real-time basis and adjusts process conditions (temperature and gas flow) to control the nitriding rate.

Typically, nitriding a sample containing the ultra-fine attritor milled silicon powder was begun by heating in vacuum to $900^{\circ} \mathrm{C}$. A mixture of $95 \%$ nitrogen/ $5 \%$ hydrogen gas was then allowed to flow into the furnace. The furnace was heated $\left(20^{\circ} \mathrm{C} / \mathrm{min}\right)$ to $1100^{\circ} \mathrm{C}$, at which point the nitriding reaction begins to occur. The temperature was then ramped to $1200^{\circ} \mathrm{C}$ at $0.5^{\circ} \mathrm{C}$ per minute while the pressure was automatically maintained within 5 torr of ambient pressure by adjing nitrogen as it was consumed by the reaction. 


\section{FIBER DEGRADATION IN THE NITRIDING ENVIRONMENT}

Fibers examined included Nicalon Ceramic Grade Si-C-O Fibers (Lot \# 072, obtained from Dow Corning), HPZ (Lot \# 11093903-3, Dow Coming),Tonen TSiNF 1021 (Tonen), and Tyranno (Lot \# 88B1611, Ube Industries). These fibers were exposed to the nitriding environment (three hours at $1200^{\circ} \mathrm{C}$ in nitrogen $/ 5 \%$ hydrogen), after which their retained strength properties were determined via single filament tensile testing.

The strength of Nicalon and several other ceramic fibers was determined both as-received and after exposure to the nitriding environment for three hours. The results for single filament tensile testing is shown in Table 2. Fibers were tested at $2^{n}$ gauge length except as indicated. The retained strength of Nicalon after nitriding appeared to be higher than the other ceramic fibers tested.

\section{TABLE 2}

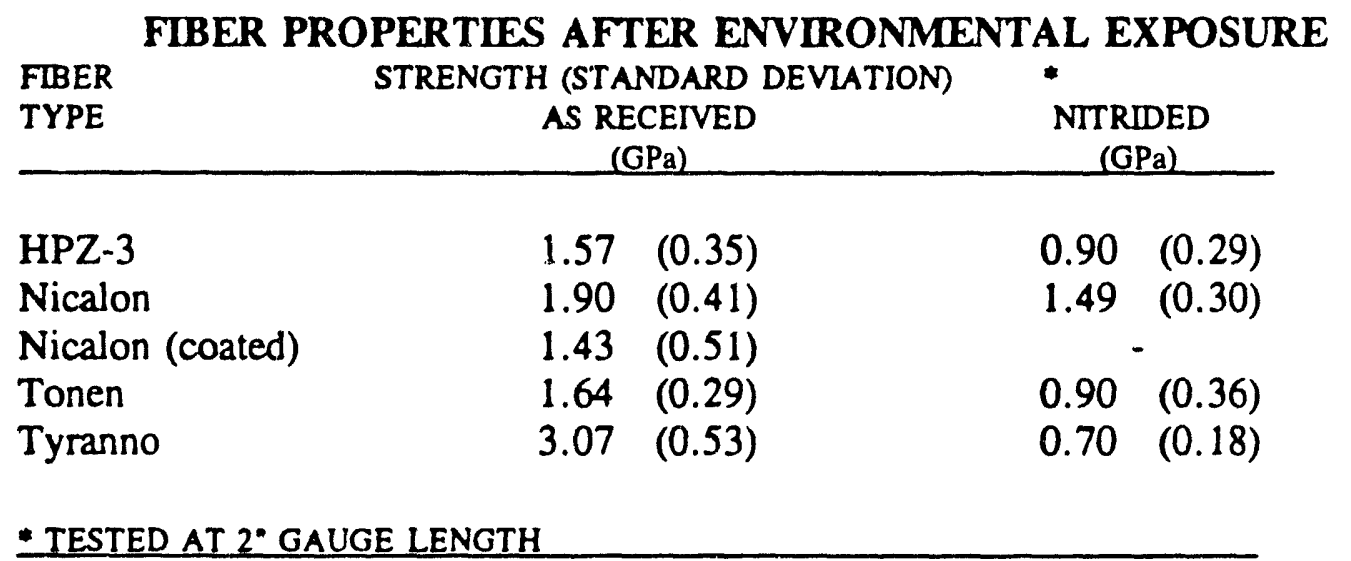

\section{FIBER COATINGS}

Nicalon fiber tow was coated via chemical vapor deposition (CVD) using the continuous fiber coating system shown in shown in Figures 1 and 2. The system consists of a conventional vertical CVD furnace with spool enclosures at the top and bottom of the furnace. A water cooled stainless steel shell surrounds a graphite heating element, which heats a 2.54 $\mathrm{cm}$ diameter graphite reaction chamber. Reactant gasses are introduced into the furnace 
through the bottom enclosure, and flow upward through a gas injector and into the coating furnace.

The Nicalon fiber was coated with thin films of carbon and silicon carbide using propylene for the carbon source reagent and methyltrichlorosilane ( $\mathrm{MTS}=\mathrm{CH}_{3} \mathrm{SiCl}_{3}$ ) as the $\mathrm{SiC}$ precursor. Each reagent was introduced through separate paths surrounding the fiber. The fiber was exposed to propylene alone for the first $15 \mathrm{~cm}$ into the furnace before being contacted with the MTS. Processing conditions include $1050^{\circ} \mathrm{C}, 0.1 \mathrm{~atm} ., 0.40 \mathrm{1} / \mathrm{min}$ of propylene, and $2.5 \mathrm{~g} / \mathrm{min}$ of MTS. Hydrogen was bubbled through the MTS liquid to carry the reagent vapor into the furnace; hydrogen also was used as a diluent. The total hydrogen flow rate was $1.5 \mathrm{l} / \mathrm{min}$. The fiber tow was pulled at a rate of $20 \mathrm{~cm} / \mathrm{min}$.

The dupiex silicon carbide/carbon fiber coating was examined via scanning electron microscopy (Figure 3). In general the coating has uniform morphology and few defects. The coated fiber tow was qualitatively more brittle than the de-sized but uncoated Nicalon, and requires more care to construct a composite specimen without breaking the fiber tow. This may be due to small amounts of bonding between adjoining coated fibers at contact points.

\section{FABRIC REINFORCED COMPOSITES}

\section{Fabrication}

Fabric reinforced composite were fabricated using five different fiber reinforcements, ${ }^{14}$ as shown in Table 3. Two carbon coated Nicalon samples were examined. One (C1) was coated as a cloth using CVD. ${ }^{13}$ On the second (C2) a carbon coating was applied to the fiber prior to weaving. A procedure was developed for preparation of composites with each of the fiber materials in Table 3. Each cloth layer was dipped in a $30 \mathrm{wt} \%$ slurry of silicon in ethanol. The impregnated cloth layers were then stacked to form the laminate and pressed between aluminum plates, removed, and placed in a refractory fixture. The laminate was placed between two perforated molybdenum plates backed by two silicon nitride plates. The assembly was compressed and shims were put into place to constrain the samples to its original pressed thickness during nitriding. The constrained sample were then nitrided. ${ }^{14}$ 


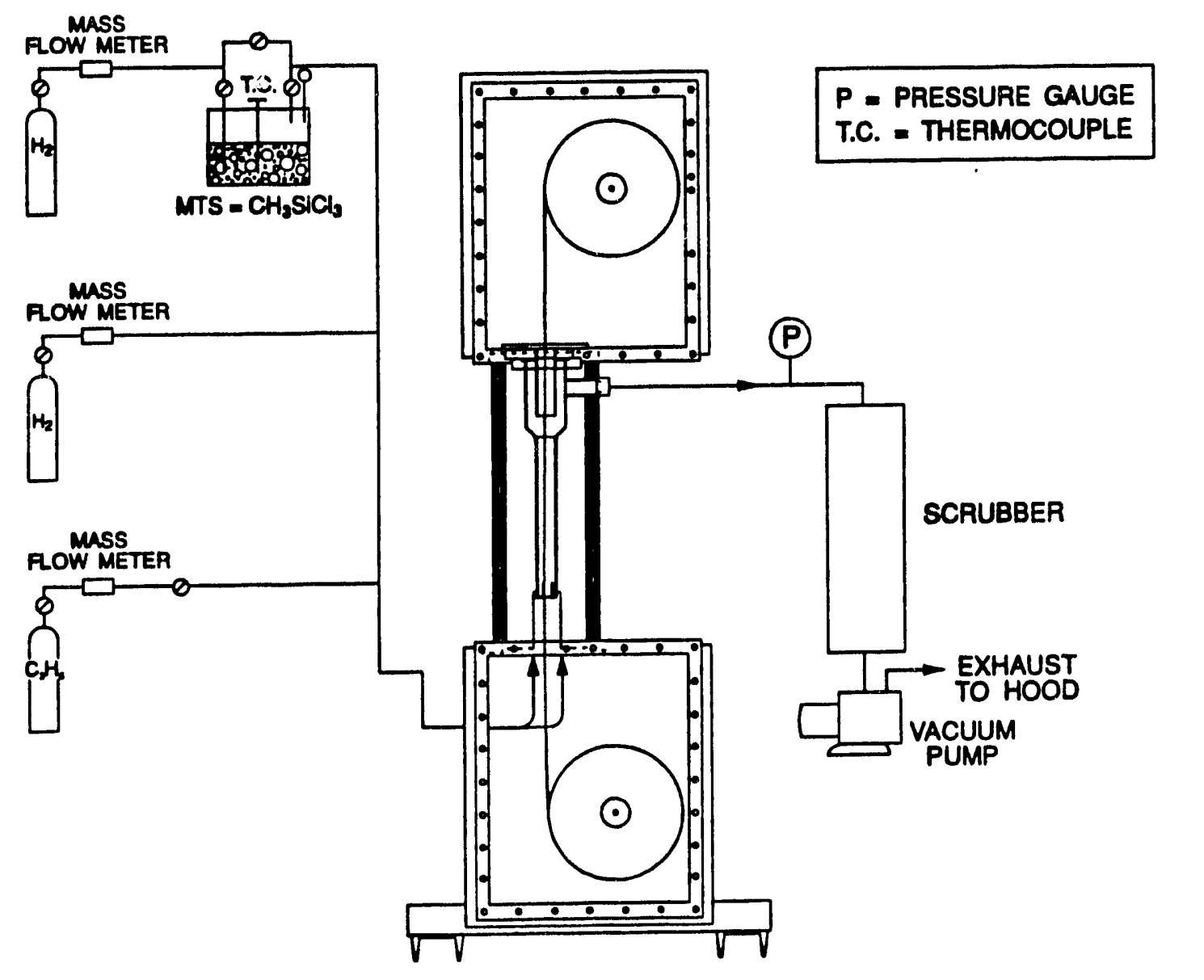

Figure 1. Chemical vapor deposition system used to deposit $\mathrm{C} / \mathrm{SiC}$ coatings on Nicalon fibers. 


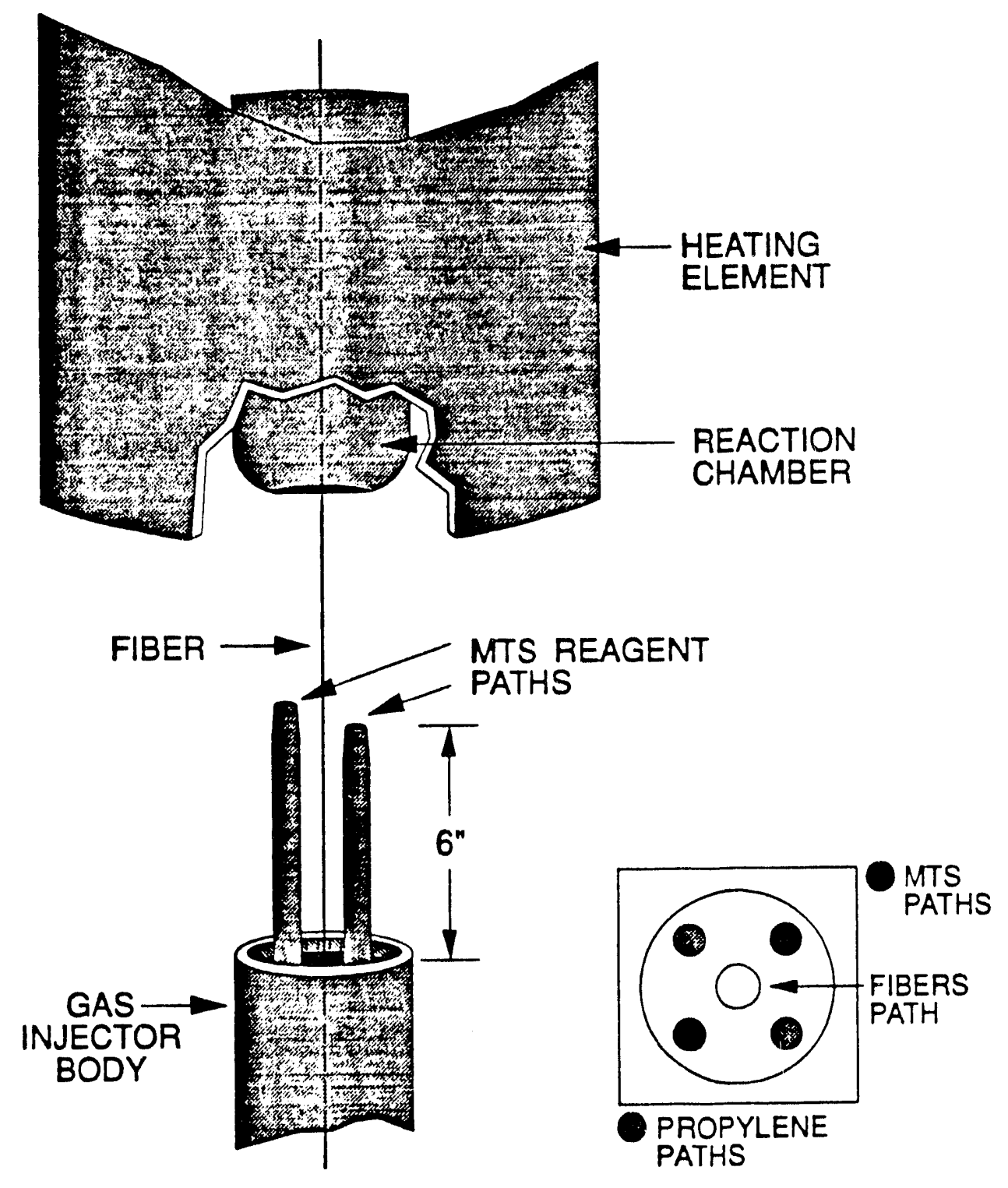

Figure 2. Schematic of the reagent introduction path used to deposit $\mathrm{C}+\mathrm{SiC}$. 


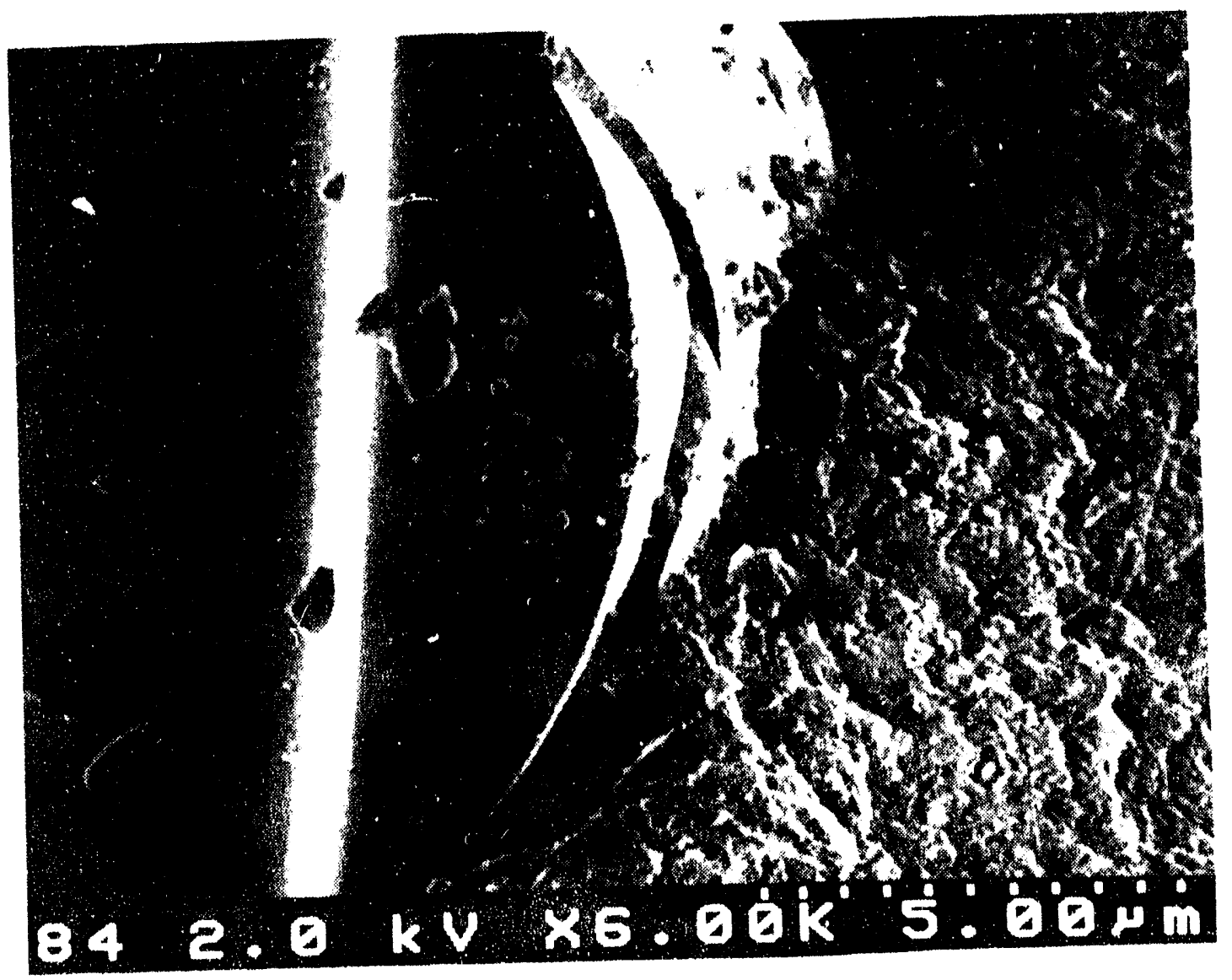

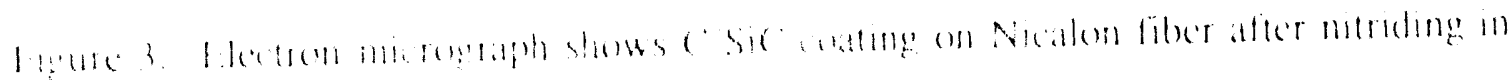
(imlpuill:

TABIE: 3

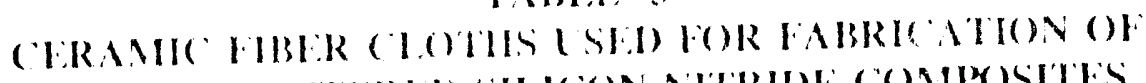

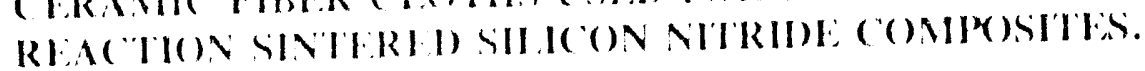

$(1,111$

\begin{tabular}{|c|c|}
\hline $1.11 x+5$ & Alcial \\
\hline 1)iatmoled & 1)(msily \\
\hline$(\mu m 11)$ & (minglor \\
\hline
\end{tabular}

Niantin

1218

37

XIS

l

11).1?

S115

$111 \%$

11) 1?

11

sits

Natalom (')

1218

Nicullul (?

1218

si)

Sils

Mamuficturer

4

37

Heats

Mimufictures 
In addition, studies were performed to evaluate the fabrication of more complex structures using the fabric impregnation+lay-up+reaction sintering sequence. The impregnated fabric layers can be molded, for example, or assembled into a complex shape. For example, a T-section was fabricated using 16 layers of Nicalon which had been impregnated with a $\mathbf{4 0}$ wt \% slurry of silicon in ethanol. The assembly was then nitrided. Many complex shapes could be fabricated by this method.

\section{Characterization}

Flat fabric reinforced plate specimens have been fabricated as described above. ${ }^{14}$ Microscopic inamination of the composites showed good density between the tows, but significant porosity within the individual tows ${ }^{14}$. Flexural test bars were cut from the composite plates and tested in four-point bending configuration with the stress plane either parallel or perpendicular to the cloth layers. All specimens exhibited some non-brittle fracture behavior, i.e. continued to carry some load after crack initiation. Except for a few cases, the bars remained intact throughout the test.

\section{UNIAXIAL CONTINUOUS FIBER COMPOSITES}

\section{Fabrication}

Filament wound composite samples were produced (Figure 4) with a fiber tow spacing of 0.05 $\mathrm{cm}$ per turn of the mandrel. Tows were impregnated with a slurry of attritor milled silicon powder in ethyl alcohol with the addition of a fugitive binder (Methocel A14LV PREM, Dow Chemical Company) and, in some cases, a dispersant (a sodium salt of a carboxy functional polymer (Tamol 731, Rohm and Haas Company)). Flat plate samples were produced by winding the impregnated tow onto a mandrel with square cross-section, then clamping each face holding a resultant uniaxial composites until dry. Each laminate was removed from the mandrel, dimensionally constrained in a refractory fixture (similar to the molybdenum and silicon nitride assembly described above), then nitrided. 
Cylindricai samples were fabricated by winding four to eight layers of impregnated ceramic fiber tow (as above) onto a mandrel to achieve a fiber spacing of $0.05 \mathrm{~cm}$. The samples were dried then nitrided on the mandrel.

Uniaxial composite samples were also fabricated using coated fiber samples. Fibers were aligned uniaxially with approximately $0.05 \mathrm{~cm}$ spacing between tows. They were then impregnated with a slurry of attritor milled silicon powder in ethanol to make a "tape-preg". The tape-preg was then stacked to form a 12 layer laminate. The assembly was then clamped in a refractory fixture then nitrided.

\section{Characterization}

Uniaxial flat plate samples (produced by impregnating the individual fiber tows with silicon powder then assembling them using filament winding) exhibited better impregnation of matrix material into the fiber bundle than the fabric reinforced samples (Figure 5). Typical properties for these samples are also shown in Table 6. Mechanical properties were evaluated using four point flexure tests (following Mil. Std. 1942 size B) for flat plates and the c-ring technique ${ }^{14}$ for tubular specimens (Figure 6). Flexural test bars were cut from the composite plates and tested in four-point bending configuration with the stress plane either parallel or perpendicular to the plane of the sample plate. Strengths as high as $200 \mathrm{MPa}$ have been exhibited by individual samples. The apparent location of large flaws was between adjacent bundles in the uniaxial structure rather than inside of the fiber bundles.

Tubular samples were also produced by filament winding. The combination of filament winding with reaction sintering was a relatively simple way to make cylindrical composites. The size of components made in this manner should only be limited by the capacity of the filament winder and nitriding furnace, making the fabrication of larger articles uncomplicated. These samples were tested using the "C-ring" technique described in the experimental section. Data for selected samples is shown in Table 4.

The failure mode in all of the filament wound samples tested in flexure (including the " $\mathrm{C}$-ring tests, which are essentially flexure tests) was apparently more interlamellar than tensile. The crack appeared to propagate through the matrix causing delamination (Figure 6). Thus, the measured flexure strength was more dependent on the matrix shear strength than on the fiber 
properties. Further investigation using tensile testing for flat plate samples is required to verify the ultimate strength of this composite system.

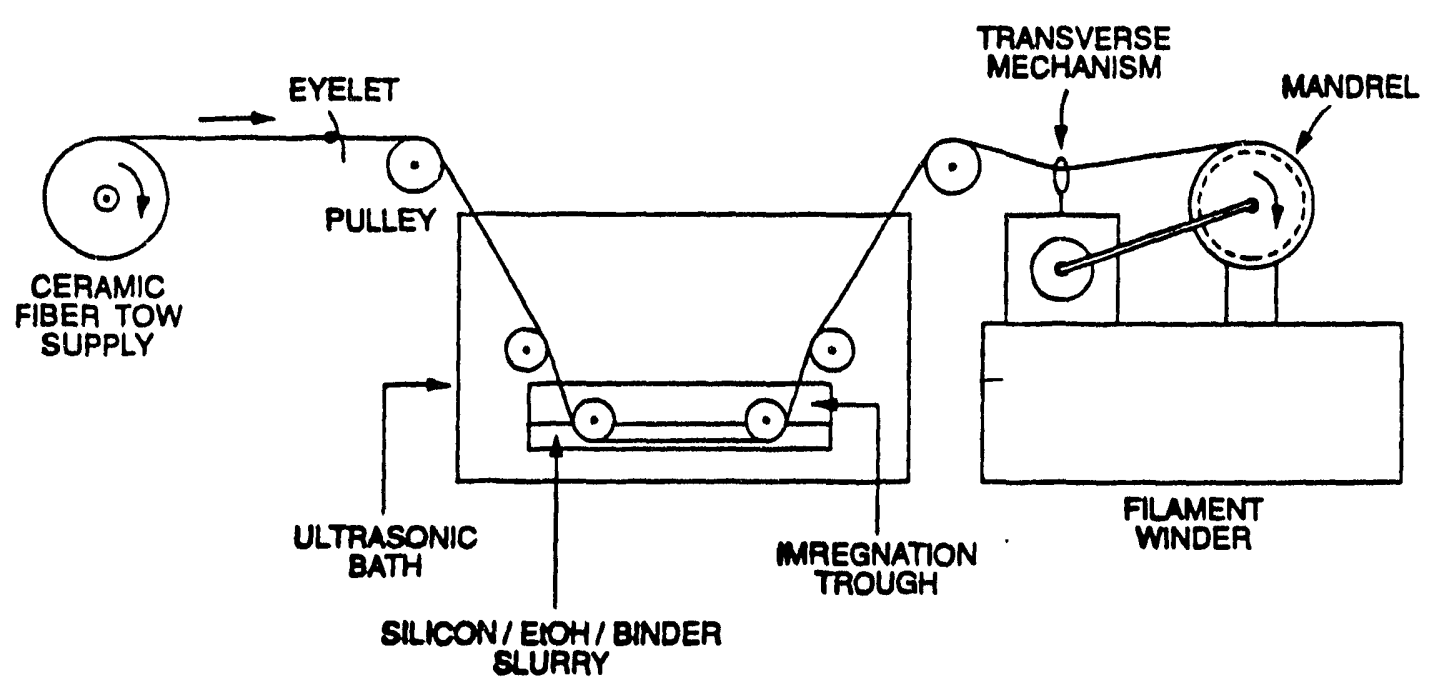

Figure 4. Filament winding apparatus for reaction sintered composites. 


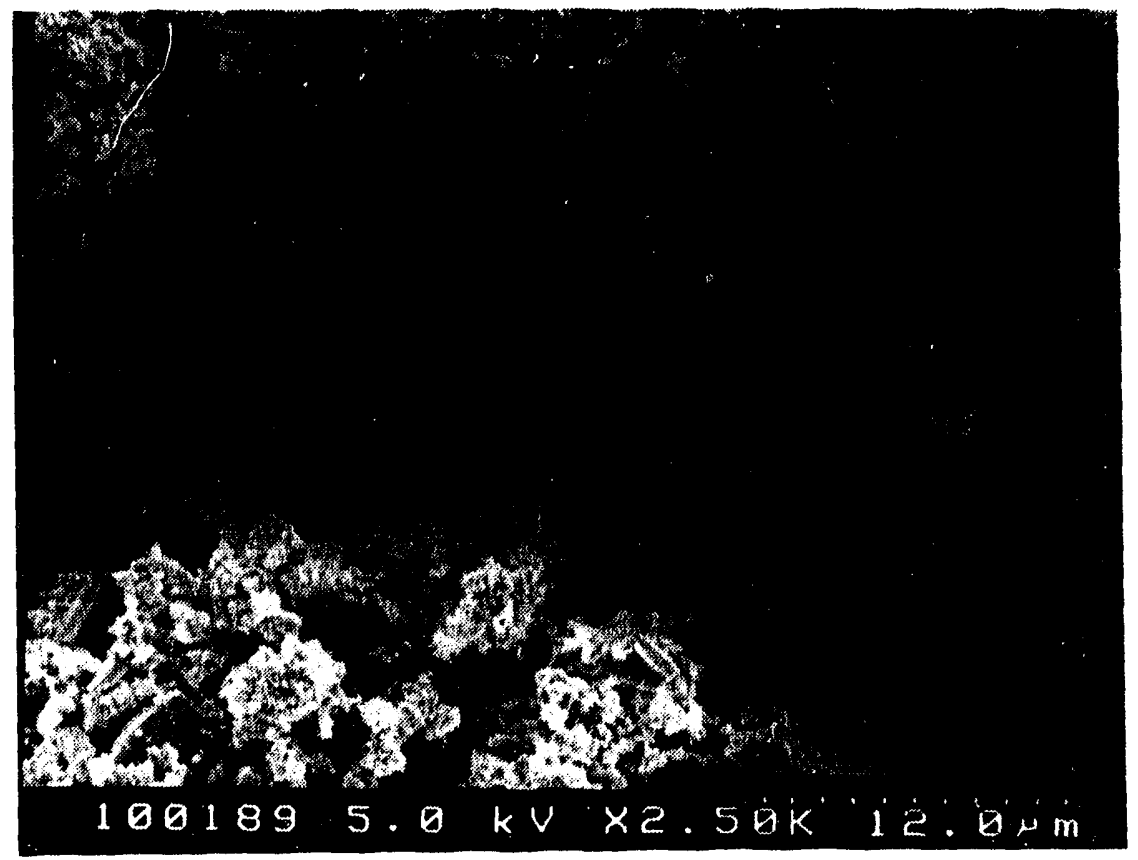

Figure 5. Uniaxial Nicalon/reaction sintered silicon nitride microstructure. 


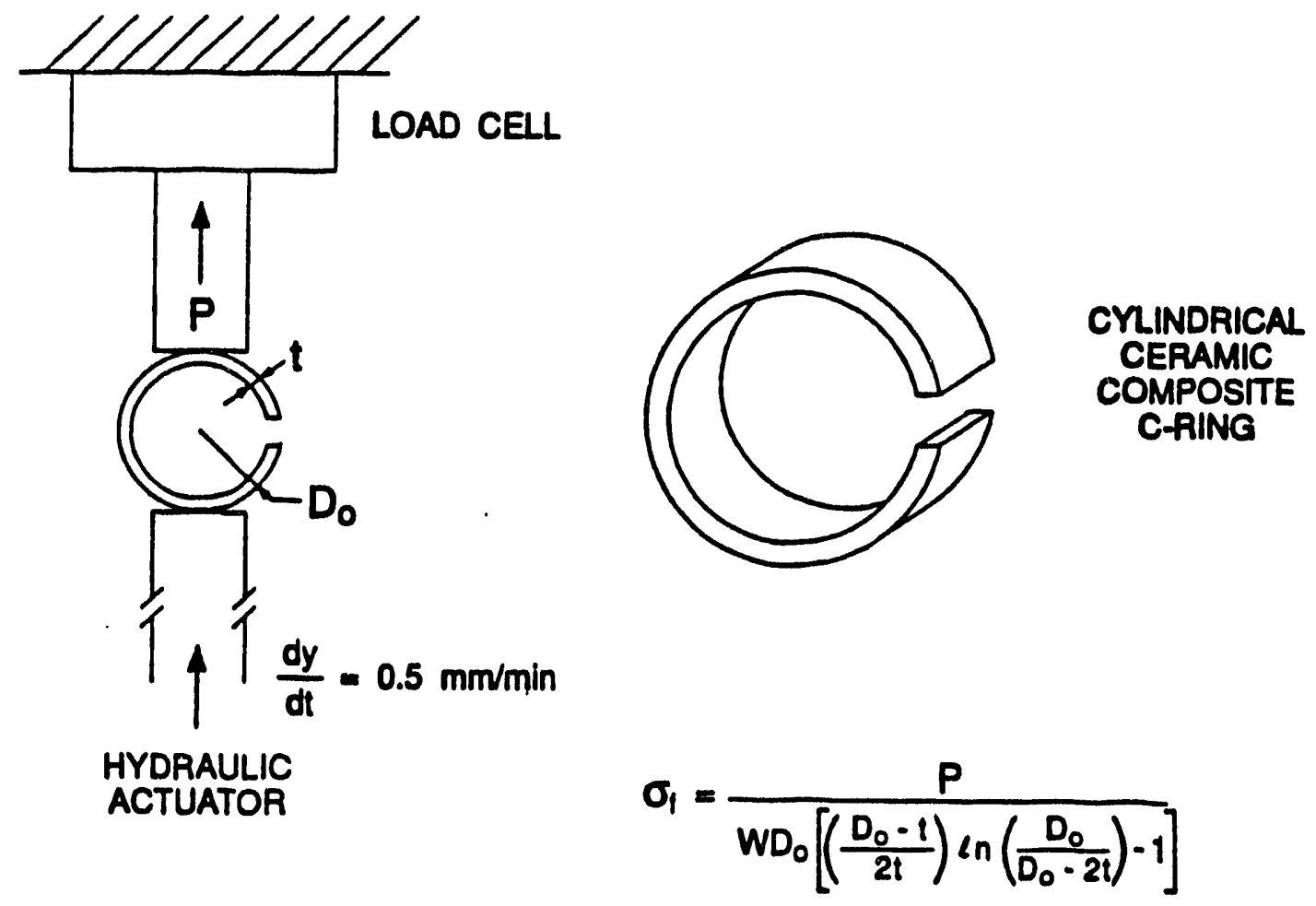

Figure 6. C-ring test configuration used to test tubular samples.

TABLE 4

SUMMARY OF TYPICAL SILICON NITRIDE COMPOSITE PROPERTIES

\begin{tabular}{llccc} 
COMPOSITE & FIBER & \multicolumn{3}{c}{ STRENGTH OMPa) } \\
TYPE & TYPE & TEST & PARALLEL & PERPENDICULAR \\
\hline & & & & 85 \\
FABRIC & NICALON & MOR & 72 & 116 \\
FABRIC & COATED NICALON & MOR & 92 & 65 \\
FABRIC & HPZ & MOR & 44 & \\
& & & & 175 \\
UNIAXIAL & NICALON & MOR & 126 & 86 \\
UNLAXIAL & HPZ & MOR & 70 & 147 \\
UNUXIAL & COATED NICALON & MOR & 61 & - \\
CYLINDER & NCALON & C-RING & 126 & - \\
CYILINDER & CARBON & C-RING & 152 & \\
\hline
\end{tabular}


Uniaxial plate samples were also prepared using the coated fiber samples described earlier. A comparison of density and strength data for these samples is shown in Table 5. The coating appeared to protect the fibers in the nitriding environment (Figure 3). However, because the coating process was in the early stages of development, apparently some bonds were formed at fiber cross-over points in the fiber tow. These bonds caused an increase of stiffness of each individual tow, making it difficult to fabricate a composite without breaking the tow. Progress in our experimental techniques since these early samples were produced should reduce bonding in future coated fibers samples.

TABLE 5

FLAT PLATE UNIAXIAL COATED FIBER LAMINATES

MICALON FIBER TYPE: UNITS SIC/C COATED UNCOATED

\section{DENSITY}

VOLUME FRACTION

MOR (PERPENDICULAR)

MOR (PARALLEL)

\begin{tabular}{cc}
$\left(\mathrm{g} / \mathrm{cm}^{3}\right)$ & 2.15 \\
(\% Fiber/Matrix/Pores) & $48 / 31 / 21$ \\
$(\mathrm{MPa})$ & 147 \\
$\mathrm{MPa})$ & 61 \\
\hline
\end{tabular}

2.11

$36 / 38 / 24$

175

126
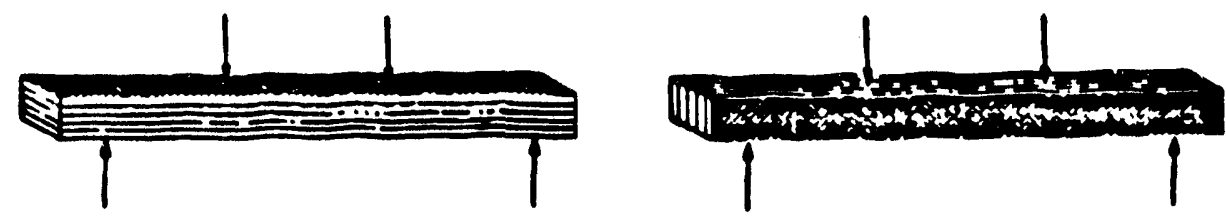

FIGURE 7. PARALLEL AND PERPENDICULAR SAMPLE CONFIGURATIONS. 


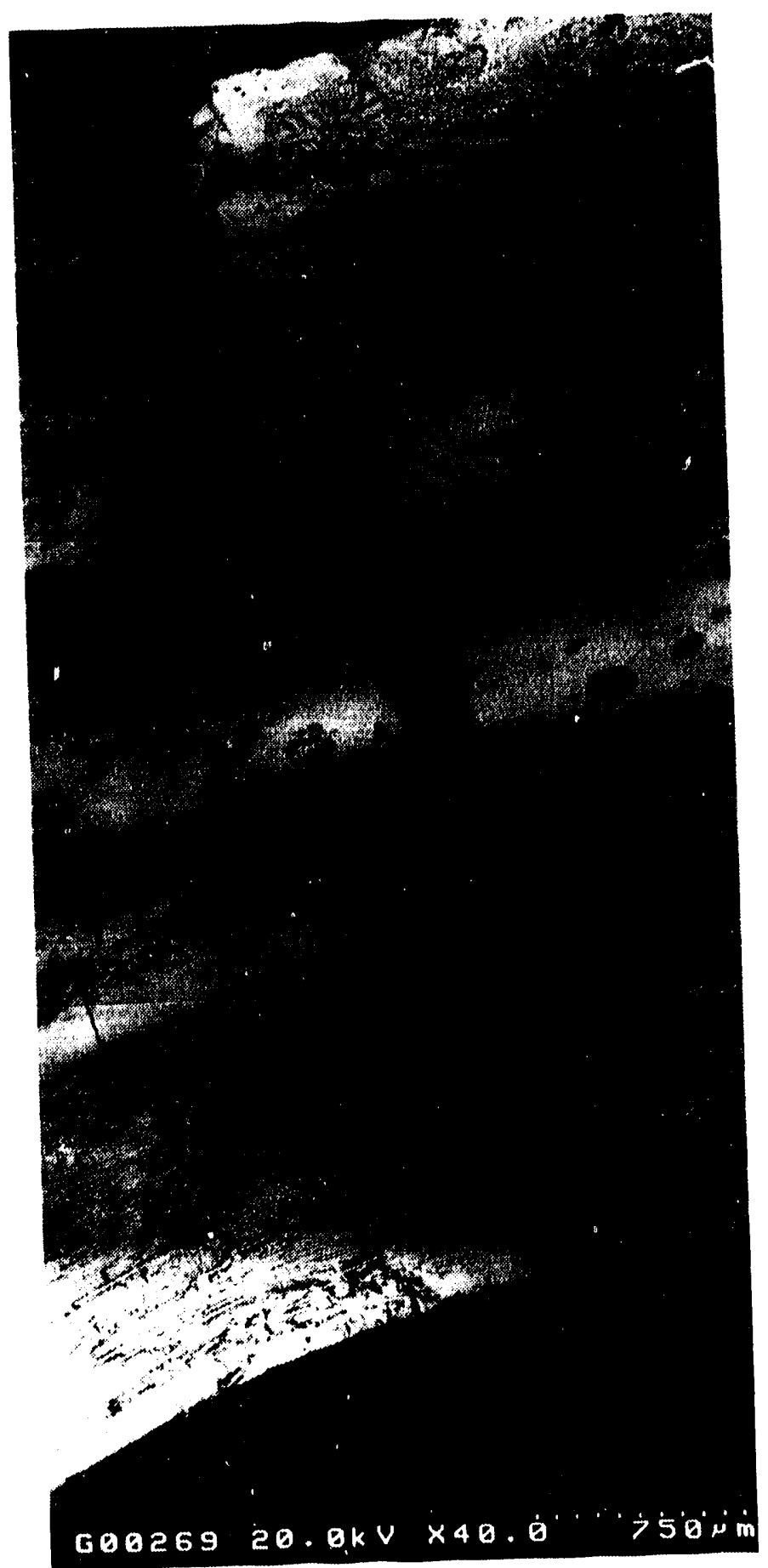

Figure 8. Crack propagation in uniaxial Nicalon/reaction sintered silicon nitride composite. 


\section{DISCUSSION AND CONCLUSIONS}

The effect of the nitriding conditions on the properties of commonly available ceramic fibers was investigated. The fibers exhibited a significant reduction in strength after exposure to the nitriding conditions, and the various fiber types ended up with approximately similar properties. Degradation of the fibers was visually observed in electron microscopy.

Because fiber strength retention is critical to achieving improved composite properties, the development of a protective coating system for ceramic fibers is cf great interest. A continuous duplex $\mathrm{C} / \mathrm{SiC}$ coating was deposited onto Nicalon via CVD. The coating appeared to reduce visible degradation in the nitriding environment (as observed via electron microscopy). More development is needed to produce: a) fiber coatings which do not decrease the flexibility of the tows; and b) good reaction sintered composites which incorporate such coated fibers.

A variety of shaped Nicalon reinforced composite articles have been produced using cloth layup or filament winding followed by the reaction sintering process. Filament winding was used to make flat plates and tubular shapes. These samples had good densities and improved microstructure compared to the fabric reinforced samples. We observed good penetration of matrix material into the fiber tows in the filament wound samples. Strengths of these samples were also higher than the fabric reinforced samples. Individual samples exhibited strengths as high as $195 \mathrm{MPa}$ in flexure.

Uniaxial reaction sintered composites were fabricated using the $\mathrm{C} / \mathrm{SiC}$ coated Nicalon fibers. These samples had reasonable strengths, but variabilities in the processing techniques and processibility of the coated fibers caused the samples to be somewhat deficient in matrix material. The primary failure mode in flexure for the filament wound samples was via shear failure in the matrix material, so the lower content of matrix naterial in the coated fiber samples resulted in lower strength values than the strongest filament wound samples. Additional development of the fiber coating process has been performed that should enable the production of coated fiber tows that are easier to handle so that composites with appropriate fiber and matrix content can be fabricated. This would allow composites to take advantage of the potential fiber stability/interfacial strength control benefits that the coated fiber system may offer.

The techniques developed in this program for fabrication of composites using polymer matrix composite processing methods allow simplified fabrication of ceramic composite structures. For 
example, a fabric layer impregnated with silicon powder and a binder could be laid up to form a laminate to make a wide variety of shaped objects. Once a laminate has been assembled, it can be constrained in a refractory fixture (which could be shaped to act as a matched die mold) and subsequently nitrided with other parts en masse. Other techniques, such as filament winding, lend themselves to automation to produce shaped articles. Complex component shapes can be fabricated using multiaxial winding or braiding machines followed by the same processing sequence of tow impregnation-shape fabrication-shape fixation-nitriding to produce ceramic composites.

The combination of common polymer matrix composite fabrication techniques used in industry with the reaction sintering process using submicron attritor milled silicon powder has been shown to be a viable alternative for the production of relatively low cost, near-net-shape ceramic composite components. Uniaxial reinforced reaction sintered composites have properties comparable to CVI densified composites, with reasonable strengths and graceful fracture behavior. Development of improved fiber coatings and optimization of composite fabrication techniques should allow for the cost-effective fabrication of ceramic composites.

\section{REFERENCES}

'W. J. Lackey and T. L. Starr, in Eiber Reinforced Ceramic Composites, Materials, Processing and Technology, Ed. by K. S. Mazdiyasni, Noyes Publications, Park Ridge NJ, 397-450 (1990). ${ }^{2}$ R. T. Bhatt, "Effects of Fabrication Conditions on the Properties of SiC Fiber Reinforced Reaction-Bonded Silicon Nitride Matrix Composites (SiC/RBSN)", in Metal Matrix. Carbon and Ceramic Matrix Composites, NASA Conf. pub. 2445, 277-295 (1986).

${ }^{3}$ T. L. Starr and J. N. Harris, "Development of Advanced Fiber Reinforced Ceramics", Georgia Tech Final Report for DOE Fossil Energy Matreials Program, Oak Ridge National LaboratoryReport ORNL/Sub/83-43369/01 (December 1986).

"O. J. Gregory and S. B. Lee, "Reaction Sintering of Submirometer Silicon Powder", J. Amer. Ceram. Soc. , 70(3), C52-C55 (1987).

5B. W. Sheldon and J. S. Haggerty, Cer. Eng. Sci. Proc., 9 [7-8], $1061-1072$ (1988).

${ }^{6}$ T. L. Starr, J. S. Lyons, J. N. Harris, and D. L. Mohr, "Process Development for Reaction 
Sintered Silicon Nitride Composites", 3rd Annual Conf. Fossil Energy Mat'ls (August 1989).

'E. Fitzer and R. Gadow, "Fiber-Reinforced Silicon Carbide", Amer. Cer. Soc. Bull., 65 [2], 326-335 (1986).

'T. W. Coyle, H. M. Chan, and U. V. Deshmukh, in Interfaces in Polymer. Ceramic, and Metal Matrix Composites, p. 489, Elsevier, New York (1988).

'G. B. Freeman, T. L. Starr, J. N. Harris, R. E. Kirchain, and D. L. Mohr, "Characterization of the Fiber-Matrix Interfaces in a SiC-Si $\mathrm{N}_{4}$ Ceramic Composite System", Heat-Resistant Materials, Proceedings of the First International Conference, Fontana, Wisconsin, p. 299 (1991). ${ }^{10}$ J. R. Strife and J. E. Sheehan, "Ceramic Coatings for Carbon-Carbon Composites", Amer. Cer. Soc. Bull., 67 [2], 369-374 (1988).

"D. L. Mohr and T. L. Starr, "Polyorganosilazane Preceramic Binder Development for Keaction Bonded Silicon Nitride Composites", Topical Report, DOE Contract No. DE-AC05-840R211400 sub/19X-00184C, for Oak Ridge National Laboratory (November 1992).

${ }^{12}$ D. L. Mohr, T. L. Starr, and J. N. Harris, "Intelligent Control of Advanced Ceramic Processing", Cer. Eng. Sci. Proc., 10 [9-10], 414-1424 (1989).

${ }^{13}$ R. A. Lowden and D. P. Stinton, "The Influence of the Fiber-Matrix Bond on the Mechanical Behavior of Nicalon/SiC Comspoites", Oak Ridge National Laboratory Report TM-10667 (December 1987).

${ }^{14}$ T. L. Starr, J. N. Harris, D. L. Mohr, and J. S. Lyons, "Development of Continuous Fiber Reinforced Silicon Nitride", Interim Report, Oak Ridge National Labs DE-AC05-840R21400 sub/19X-00184C (August 1990).

${ }^{15}$ D. P. Butt, J. J. Mecholsky, Jr., M. van Roode, and J. R. Proce, "Effects of Plasma- Sprayed Ceramic Coatings on the Strength Distribution of Silicon Carbide Materials", J. Am. Cer. Soc., 73 [9], 2690-96 (1990). 
A.P. GREEN REFRACTORIES COMPANY

Groen Blvd.

Medico, MO 65265

J. L. Hill

AIR PRODUCTS AND CHENICAIS

P.O. Bax 538

Alleatown, PA 18105

S. W. Dean

S. C. Weiner

ALISON GAS TURBDE DIVISION

P.O. Bar 420

Indinnapolis, IN $\mathbf{6 2 0 0 6 - 0 4 2 0}$

P. Khandetwal (Speed Code W.S)

R. A Wenglarz (Speed Code W-16)

AMA RESEARCH \& DEVELOPMENT CENTER S950 McIntyre Street

Golden, 00803

T. B. $\operatorname{Cox}$

ARGONNE NATIONAL LABORATORY

9700 S. Cass Avenue

Argonne, II 60439

W. A. Ellingson

J. P. Singh

ARMY MATERIALS TECHNOLOGY

LAPORATORY SLCMT-MCC

Wai_i_own, MA 02172-0001

D. R. Messier

AVCO RESEARCH LABORATORY

2385 Revere Beach Partway

Everett, MA 02149

R. J. Pollina

BABCOCK \& WILCOX

1562 Beeson St.

Alliance, OH 44601

T. 1. Johnson

BABCOCK \& WIDCOX

Domestic Fosil Operations

20 South Van Buren Avenue

Barterton, OH 44023

M. Gold

BRTISH COAL CORPORATION

Col Research Establishment

Stoke Orchard, Cbeltenham

Glocbester, England GLS2 4RZ

M. Arnold

C. Bower

A Twigs
BRIIISH GAS CORPORATION

Weafield Development Center

Cardenden, Fife

Scotland KYSOFIP

J. E. Scott

BROOKHAVEN NATIONAL LABORATORY

Department of Applied Science

Upton, Long Inind, NX 11973

T. E. OHare

CANADA CENTER FOR MUNERAL \& ENERGY TECHNOLOGY

568 Booth Street

Ottawn, Ontario

Cansoda K1A OG1

R. Winetoo Revic

Mahi Saboo

DOW CORNDNG CORPORATION

3901 S. Saginaw Road

Midland, MI 48686-0995

H. Arwell

EC TECHNOLOGIES

3614 Highpoint Drive

San Antooio, TX 78217

D. J. Kenton

ELECTRIC POWER RESEARCH DNSTITUTE

P.O. Box 10412

3412 Hillview Avenue

Palo Ato, CA 94303

W. T. Bakker

J. Stringer

EUROPEAN COMOMUNITIES JODNT RESEARCH CENTRE

Petten Establishment

P.O. $\operatorname{BOx} 2$

1755 ZG Petten

The Netberlands

M. Van de Voorde

GA TECHNOLOGLE. INC.

P.O. Bar 85608

San Diego, CA 92138

T. D. Gulden

GEORGLA INSTITUTE OF TECHNOLOGY

Georgia Tech Research Institute

Allanta, GA 30332

T. L Start 
IDAHO NATIONAL ENGNEERING

LABORATORY

P. O. Box 1625

Idabo Falls, ID 83415

D. W. Keefer

B. H. Rabin

LENNAMETAI, DNC.

Philip McKenas Laboratory

1011 Old Salem Rosd

P. O. Bar 639

Greensburg, PA 15601

B. North

LAVA CRUCIBLE-REFRACTORIES CO.

P.O. BOx 278

Zelienople, PA 16063

T. Mulholland

LAWRENCE LIVERMORE LABORATORY

P.O. Box 808, L-325

Livermore, CA 94550

W. A. Steele

NATIONAL DNSTITUTE OF STANDARDS AND TECHNOLOGY

Materials Building

Gaithersburg, MD 20899

A. Pechenik

NATIONAL MATERIALS ADVISORY BOARD

National Research Council

2101 Constitution Avenue

Washington, DC 20418

K. M. Zwilsky

NEW ENERGY AND DNDUSTRIAL TECHNOLOGY DEVELOPMENT

Sunshine 60 Bldg.

P.O. Box 1151

1.1 Higashi-Ikebukuro 3-Chrome

Toshima-Ku, Tokyo, 170

Japan

H. Narita

S. Ueda

THE NORTON COMPANY

High Performance Ceramics Division

Goddard Roed

Nortbborough, MA 01532-1545

N. Corbin
OAK RIDGE NATIONAL LABORATORY

P.O. Box 2008

Oak Ridge, TN 37831

P. T. Cartoon

N. C. Cole

R. R. Juditios

R. A. Lumon (8 copies)

D. P. Stinton

OFFICE OF NAVAL RESEARCH

Code 431, 800 N. Quincy Street

Astington, VA 22217

S. G. Fumman

RESEARCH TRIANGLE INSTITUTE

P. O. Bar 12194

Research Triangle Part, NC 27709

T. W. Sigmon

SHELL DEVELOPMENT COMPANY

P.O. Box 1380

Houston, TX $77251-1380$

L.W. R. Dicts

TENNESSEE VALIEY AUTHORTY

Energy Demonstration \& Technology

MR2N58A

Chattanooga, TN 37402-2801

C. M. Huang

3M COMPANY

Ceramic Materials Department

201-2C-12 3M Center,

St. Paul, MN 55144

M. A Leitbeiser

THE JOHNS HOPKINS UNIVERSTTY

Materials Science \& Engineering

Maryland Hall

Baltimore, MD 21218

R. E Green, Jr.

THE MATERIALS PROPERTIES COUNCH, INC.

United Engineering Center

345 E. Forty Seventh Street

New Yort, NY 10017

M. Prager

THE TORRDNGTON COMPANY

Advanced Technology Center

59 Field St.

Torrington, CT 06790

w. J. Chmure 
UNION CARBIDE CORPORATION

Inde Division

P.O. Bar 44

175 Bast Part Drive

Tonswanda, NY 14151-0044

Hanty Coeung

UNITED TECHNOLOGIES RESEARCH CENTER

MS 24, Siver Lane

Bint Hartiond, CT 06108

R M. Prewo

UNTVERSTTY OF WASHWNGTON

Department of Materials Science and Eogineering

101 Wilson, FB-10

Seattle, WA 98195

T. G. Stoebe

VIRGINIA POLYTECHNIC INSTITUTE \& STATE UNIVERSITY

Department of Materials Engineering

Blactburg, VA 24601

K L. Reifsnider

WESTERN RESEARCH INSTITUTE

$365 \mathrm{~N}$. 9h Street

P.O. Box 3395

University Station

Laramic, WY 82071

V. K. Sethi

WESTINGHOUSE ELECTRIC CORPORATION

Research and Development Center

1310 Beulab Road

Pittsburgh, PA 15235

S. C. Singhal

DOE

DAHO OPERATIONS OFFICE

P. O. Box 1625

Idabo Falls, ID 83415

R. B. Loop

DOE

DOE OAK RIDGE FIELD OFFICE

P.O.Bax 2001

Ouk Ridge, TN 37831

Amsistant Manager for Encrgy Research and Development

DOE

DOE OAK RIDGE FIELD OFFICE

P. O. Bar 2008

Building 4500N, MS 6269

Oak Ridge, TN 37831

E E Hoffiman
DOE

OFFICE OF BASIC ENERGY SCIENCES

Materials Sciedces Division

ER-131 GTN

Wrehington, DC 20545

J. B. Darty

DOE

OFFICE OF CONSERVATION AND

RENEWABLE ENERGY

CE-12 Forreatal Bullding

Washington, DC 20545

J. J. Ebertardt

DOE

OFFICE OF FOSSI ENERGY

Weshington, DC 20545

J. P. Cart (FE-14) GTN

DOE

OFFICE OF VEHICLE AND ENERGY R\&D

CE-151 Forreatal Building

Washingion, DC 20585

R. B. Schute

DOE

MORGANTOWN ENERGY TECHNOLOGY CENTER

P.O. Box 880

Morgantown, WV 26505

R. A. Bajura

R. C. Bedick

D. C. Cocero

F. W. Crouse, Jr.

N. T. Holcombe

W. J. Huber

M. J. Maytield

J. E Norestein

J. S. Wikson

DOE

PITTSBURGH ENERGY TECHNOLOGY CENTER

P.O. Baw 10940

Pitusburgh, PA 15236

A. L. Baldwin

G. V. MoGurt

R. Santore

T. M. Torko

DOE

OFFICE OF SCIENTIFIC AND TECHNICAL

DNFORMATION

P. O. $\mathrm{Ban} 62$

Oak Ridge, TN 37831

For distribution by microficte as sbown in DOEMIC. 4500, Distribution Category.

UC-114 (Coal Based Materials and Components) 

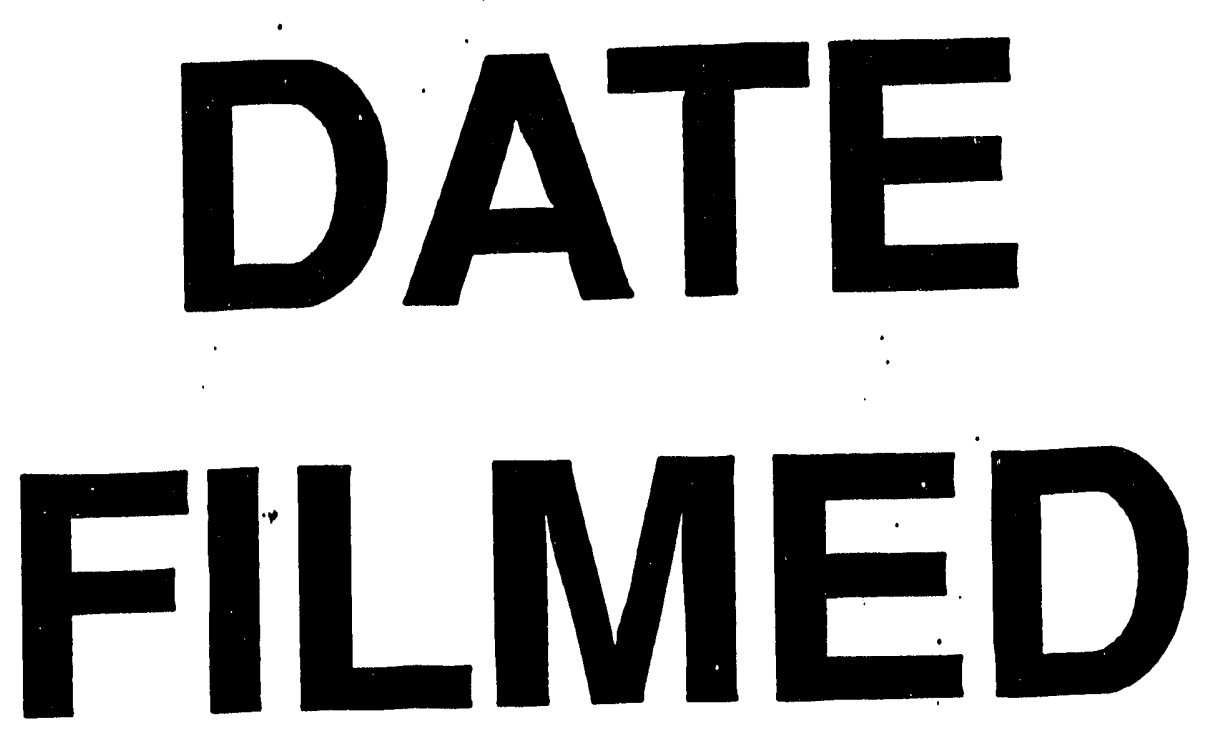

$12 / 01 / 93$
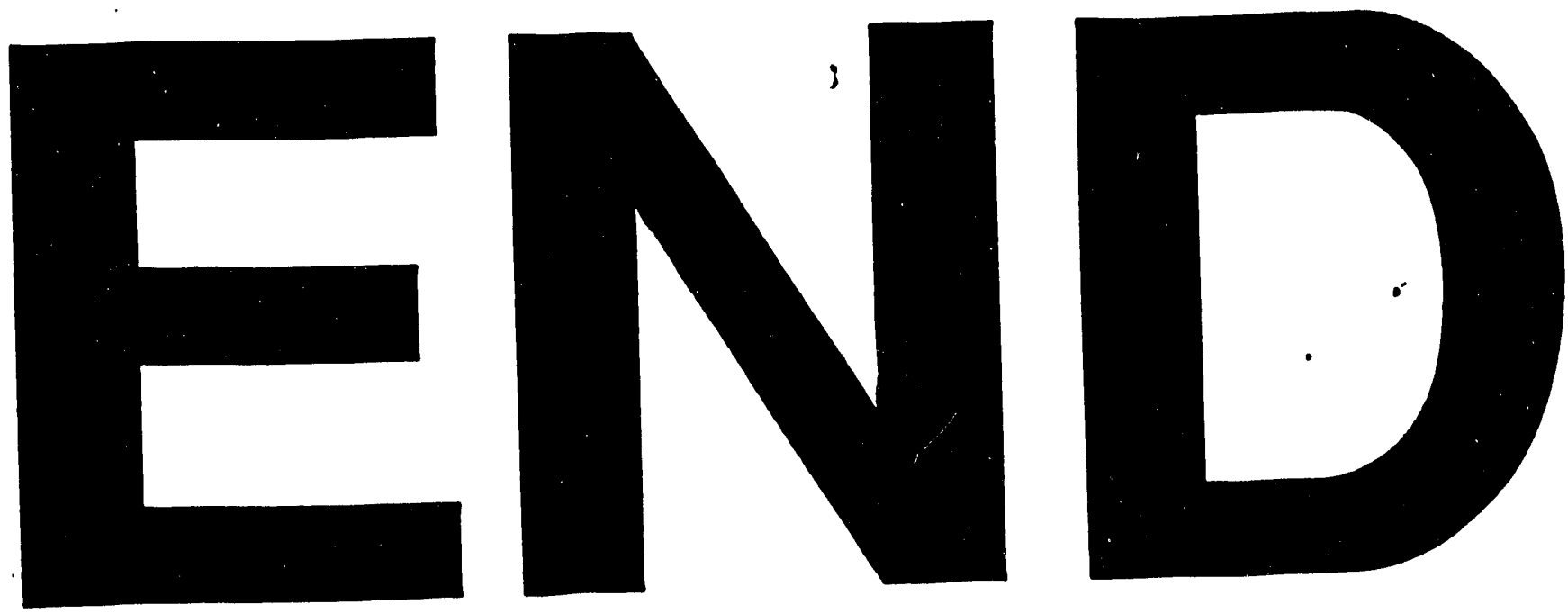
. 